\title{
Imaging DivIVA dynamics using photo-convertible and activatable fluorophores in Bacillus subtilis
}

\author{
Juri N. Bach, Nadine Albrecht and Marc Bramkamp* \\ Department of Biology I, Ludwig-Maximilians-University, Munich, Planegg-Martinsried, Germany
}

\author{
Edited by: \\ Catriona Donovan, \\ Ludwig-Maximilians-Universität \\ München, Germany

\section{Reviewed by:} \\ Mariana Pinho, Instituto de \\ Tecnologia Quimica e Biologica, \\ Portugal \\ Martin Thanbichler, \\ Philipps-Universität Marburg, \\ Germany

\section{*Correspondence:} \\ Marc Bramkamp, Department of \\ Biology I, Ludwig-Maximilians- \\ University, Munich, Großhaderner \\ Str. 2-4, 82152 Planegg-Martinsried, \\ Germany \\ e-mail: marc.bramkamp@Imu.de
}

Most rod-shape model organisms such as Escherichia coli or Bacillus subtilis utilize two inhibitory systems for correct positioning of the cell division apparatus. While the nucleoid occlusion system acts in vicinity of the nucleoid, the Min system was thought to protect the cell poles from futile division leading to DNA-free miniature cells. The Min system is composed of an inhibitory protein, MinC, which acts at the level of the FtsZ ring formation. MinC is recruited to the membrane by MinD, a member of the MinD/ParA family of Walker-ATPases. Topological positioning of the MinCD complex depends on MinE in E. coli and MinJ/DivIVA in B. subtilis. While MinE drives an oscillation of MinCD in the E. coli cell with a time-dependent minimal concentration at midcell, the B. subtilis system was thought to be stably tethered to the cell poles by MinJ/DivIVA. Recent developments revealed that the Min system in $B$. subtilis mainly acts at the site of division, where it seems to prevent reinitiation of the division machinery. Thus, MinCD describe a dynamic behavior in $B$. subtilis. This is somewhat inconsistent with a stable localization of DivIVA at the cell poles. High resolution imaging of ongoing divisions show that DivIVA also enriches at the site of division. Here we analyze whether polar localized DivIVA is partially mobile and can contribute to septal DivIVA and vice versa. For this purpose we use fusions with green to red photoconvertible fluorophores, Dendra2 and photoactivatable PA-GFP. These techniques have proven very powerful to discriminate protein relocalization in vivo. Our results show that $B$. subtilis DivIVA is indeed dynamic and moves from the poles to the new septum.

Keywords: division-site selection, DivIVA, dendra2, PA-GFP, photoconversion, photoactivation

\section{INTRODUCTION}

Placement of protein complexes in bacterial cells can be accomplished by energy driven systems using ATP hydrolyzing enzymes of the MinD/ParA protein family (Lutkenhaus, 2012). The Min system has been identified in rod-shaped bacteria due to its characteristic mutant phenotype. Absence of Min components leads to aberrant division resulting in small, DNA-free cells, called miniature cells (Adler et al., 1967). Electron micrographs of E. coli min mutants revealed that minicells seem to occur close to cell poles and, hence, the Min system was thought to be an active mechanism to protect the cell poles from aberrant cytokinesis (Rothfield et al., 2005; Lutkenhaus, 2007). This hypothesis was built based on data derived from E. coli as model organism. In E. coli the Min system consists of three proteins MinC, MinD, and MinE (all encoded in the so-called $\min B$ locus) (De Boer et al., 1988; Akerlund et al., 1992). MinC is an actual inhibitor of FtsZ ring formation (Bi and Lutkenhaus, 1990; Marston and Errington, 1999), with FtsZ being the first division protein localized at the new division site (Bi and Lutkenhaus, 1991). MinD is a Walker-type ATPase that binds reversibly to the plasma membrane in its ATP-bound form (De Boer et al., 1991) and recruits MinC. The ATP hydrolysis cycle leading to reversible membranebinding of MinD (and hence the MinCD complex) is stimulated by MinE (Zhao et al., 1995; Hu and Lutkenhaus, 2001). This simple feedback loop creates a robust oscillation of MinCDE in E. coli
(Hu and Lutkenhaus, 1999; Raskin and De Boer, 1999a,b) that can also be reconstructed in vitro on supported membrane surfaces (Loose et al., 2008).

Phyogenetic analyses made clear that Min proteins are conserved in many bacterial species. Among many other species Min proteins have also been identified in B. subtilis (Reeve et al., 1973; Varley and Stewart, 1992; Lee and Price, 1993). B. subtilis lacks the topological determinant MinE, but a functional homolog was found in DivIVA (Cha and Stewart, 1997; Edwards and Errington, 1997; Marston et al., 1998). Initial localization studies with DivIVA suggested that DivIVA is localized to the cell poles and at sites of ongoing septation (Marston et al., 1998). DivIVA was considered to be stably attached to the pole regions (Edwards and Errington, 1997; Edwards et al., 2000) and an intrinsic affinity for negatively curved membrane has been shown (Lenarcic et al., 2009; Ramamurthi and Losick, 2009). DivIVA recruits MinD via a bridging protein, MinJ (Bramkamp et al., 2008; Patrick and Kearns, 2008). In contrast to E. coli where the Min oscillation would leave a time-based MinC minimum around midcell, allowing FtsZ to form a functional ring here, the B. subtilis DivIVA/MinCDJ system was considered to be more static (Errington et al., 2003; Adams and Errington, 2009). However, recently new data on Min protein localization in B. subtilis suggest that components of the Min system in B. subtilis may not be static at the cell poles, but relocate from 
cells poles to active septa (Gregory et al., 2008; Bramkamp and Van Baarle, 2009; Van Baarle and Bramkamp, 2010). Thus, the actual site of action for the Min system in vegetative B. subtilis is the septum, rather than the cell pole and likely reinitiation of cell division next to a recently completed septum is prevented by action of the Min proteins (Bramkamp et al., 2008; Gregory et al., 2008; Bramkamp and Van Baarle, 2009; Van Baarle and Bramkamp, 2010). While dynamic relocation of MinC has been clearly shown, potential dynamics of other Min components in B. subtilis remained unclear. A recent study on MinJ and DivIVA using super resolution light microscopy has suggested that DivIVA may indeed be static and not dynamic. However, it was shown in this study that DivIVA accumulations at the cell poles are reduced and simultaneously the DivIVA amount at the active division site increases (Eswaramoorthy et al., 2011). Using GFP fusion proteins it is difficult to distinguish between newly synthesized and dynamic proteins. We therefore used here photoactivatable PA-GFP and photoconvertible Dendra2 fusion constructs and monitored DivIVA distribution in actively growing B. subtilis cells. Our data indicate that B. subtilis DivIVA is indeed dynamic and molecules from the cell pole (old division site) contribute to the formation of new DivIVA assemblies at the site of ongoing division. Thus, the B. subtilis Min system is dynamically relocalized within the cell cycle. Our work also highlights the potential use of photoconvertible tools in bacterial cell biology.

\section{MATERIALS AND METHODS STRAIN CONSTRUCTION}

The strains, plasmids and oligonucleotides used in this study are listed in Tables 1-3, respectively. E. coli DH5 $\alpha$ was used to amplify and maintain plasmids. DNA was digested by restriction enzymes (New England Biolabs) and all plasmids were verified by DNA sequencing. PA-GFP was amplified from pPAGFP-N1 using the primer pair PAGFP-pJPR1-f and PAGFP-pJPR1-r and Dendra2 was amplified with the primer pair Dendra-pJPR1-f and Dendra-pJPR1-r with pDendra2-N as template DNA. Both PCR products were cloned into $\mathrm{pJPR} 1$ resulting in $\mathrm{pJPR} 1-\mathrm{Dendra}$ and pJPR1-PAGFP. pJPR1-DivIVA-PAGFP and pJPR1-DivIVADendra were constructed by amplifying divIVA from genomic DNA using the primer DivIVA-PAGFP-f and DivIVA-PAGFP-r or DivIVA-Dendra-f and DivIVA-Dendra-r. The PCR products were cloned into pJPR1-PAGFP resulting in pJPR1-DivIVA-PAGFP or into pJPR1-Dendra resulting in pJPR1-DivIVA-Dendra.

\section{GROWTH CONDITIONS}

B. subtilis was grown with aeration in flasks using suitable media ( $\mathrm{LB}$ or $\mathrm{CH}$ ). Antibiotics were used when appropriate (tetracycline $10 \mu \mathrm{g} \mathrm{ml}^{-1}$; chloramphenicol $5 \mu \mathrm{g} \mathrm{ml}^{-1}$ kanamycin $5 \mu \mathrm{g} \mathrm{ml}^{-1}$ ). B. subtilis strains were always inoculated from fresh overnight cultures.

For time lapse microscopy of $B$. subtilis expressing DivIVAGFP cells were grown in $\mathrm{LB}$ to an $\mathrm{OD}_{600}$ of 1 . Cells were diluted 1:100 in fresh pre-warmed LB and mounted on pre-warmed 1\% agarose pads supplemented with LB. To inhibit protein biosynthesis LB agarose pads were supplemented with kanamycin to a final concentration of $5 \mu \mathrm{g} \mathrm{ml}^{-1}$. The agar pads were sealed using paraffin (Sigma-Aldrich; 327212) and incubated $10 \mathrm{~min}$ at $37^{\circ} \mathrm{C}$ before microscopic analysis.

Cells expressing DivIVA-Dendra or DivIVA-PA-GFP were treated as described above with the exception that growth medium and agar pads were supplemented with $1 \%$ fructose and with varying concentrations between 0.1 and $1 \%$ xylose.

\section{FLUORESCENCE MICROSCOPY}

For time lapse microscopy images were taken on a Zeiss Axio Observer Z1 microscope equipped with a Hamamatsu OrcaR ${ }^{2}$ camera. A Plan-Apochromat $100 \times / 1.4$ Oil Ph3 objective (Zeiss) was used and GFP fluorescence was visualized with filterset 38 HE eGFP shift free (Zeiss). The microscope was equipped with an environmental chamber set to $37^{\circ} \mathrm{C}$. Images were taken every $2 \mathrm{~min}$. Digital images were acquired with Zen software (Zeiss).

For photo-activation, photo-conversion and FRAP experiments a Delta Vision Elite (GE Healthcare, Applied Precision) equipped with an Insight SSI ${ }^{\mathrm{TM}}$ illumination, an X4 laser module and a CoolSnap HQ2 CCD camera was used. Images were taken with a $100 \times$ oil PSF U-Plan S-Apo 1.4 NA objective or with a $60 \times$ oil PlanApo, NA. 1.42 objective.

A four color standard set InsightSSI unit with following excitation wavelengths (DAPI $390 / 18 \mathrm{~nm}$ FITC $475 / 28 \mathrm{~nm}$, TRITC 542/27 nm, Cy5 632/22 nm); single band pass emission wavelengths (DAPI $435 / 48 \mathrm{~nm}$, FITC $525 / 48 \mathrm{~nm}$, TRITC $597 / 45 \mathrm{~nm}$, Cy5 $679 / 34 \mathrm{~nm}$ ) and a suitable polychroic for DAPI/FITC/TRITC/Cy5 were used. GFP and Dendra2 (green version) were visualized using FITC settings and converted Dendra2 was imaged using the TRITC filter. Bleaching was performed using a $405 \mathrm{~nm}$ laser $(50 \mathrm{~mW})$ with $10 \%$ power and $0.01-0.05 \mathrm{~s}$ illumination. For photo-activation of PA-GFP a $405 \mathrm{~nm}$ laser $(50 \mathrm{~mW})$ with $30 \%$ power and $0.5 \mathrm{~s}$ illumination was used. For PA-GFP fluorescence detection a FITC filter set (see above) was used (100\% power, $1 \mathrm{~s})$. Photo-conversion of Dendra2 was performed using a $405 \mathrm{~nm}$ laser $(50 \mathrm{~mW})$ with $15 \%$ power and $0.05 \mathrm{~s}$ illumination was used. Green fluorescence of Dendra was monitored using a FITC specific filter set, a TRITC specific filter set $(0.25 \mathrm{~s}$ illumination; $50 \%$ power $)$ was used to detect the photo-converted, red -shifted Dendra.

Analysis of the images was performed using Image $1.45 \mathrm{~s}$. The corrected total fluorescence (CTF) was calculated according to following formula: CTF = Integrated Density-(Area of selected cell X Mean fluorescence of unspecific background readings) (Gavet and Pines, 2010). For FRAP experiments unspecific background was subtracted for every ROI (see above). The CTF of the septa was divided by the CTF of the whole cell. The respective quotient of the unbleached spot was always set as 1 .

Final image preparation was done in Adobe Photoshop CS2 (Adobe Systems Incorporated). All imaging experiments were performed several times with biological replicates.

\section{RESULTS}

\section{TIME LAPSE ANALYSIS OF DivIVA-GFP}

Subcellular localization of DivIVA in B. subtilis has been reported in various publications (Edwards and Errington, 1997; Thomaides et al., 2001; Hamoen and Errington, 2003; Perry and Edwards, 2004; Lenarcic et al., 2009; Oliva et al., 2010; 
Table 1 | Oligonucleotides used in this study.

\begin{tabular}{lll}
\hline Oligonucleotide & Sequence & Restriction site \\
\hline DivIVA-Dendra-f & CATAAGCTTGGAGGTGGCATCATGCCATTAACG & HindIII \\
DivIVA-Dendra-r & ATGGGATCCTTCCTTTTCCTCAAATACAGC & BamHI \\
Dendra-pJPR1-f & CCGGATCCATGAACACCCCGGGAATAACCTGATC & BamHI \\
Dendra-pJPR1-r & CCCACTAGTTTACCACACCTGGCTGGGCA & Spel \\
DivIVA-PAGFP-f & CGTTAAGCTTTTTTTCTCCATCTGTG & HindIII \\
DivIVA-PAGFP-r & GCGACTAGTTTCCTTTTCCTCAAA & Spel \\
PAGFP-pJPR1-f & GCGACTAGTGTGAGCAAGGGCGAGGAGCT & Spel \\
PAGFP-pJPR1-r & AATGCGGCCGCTTACTTGTACAGCTCGTC & Notl
\end{tabular}

Table 2 | Plasmids used in this study.

\begin{tabular}{lll}
\hline Plasmid & Characteristics & Reference/source \\
\hline pDendra2-N & pUC ori, SV40 ori, PCMVIE, Kan ${ }^{r}$ & Evrogen \\
pPAGFP-N1 & pBR322 ori, f1 ori, PCMVIE, Kan ${ }^{r}$ & Addgene \\
pJPR1 & bla amyE3' cat Pxyl amyE5' & Bramkamp et al., 2008 \\
pJPR1-Dendra & bla amyE3' cat Pxyl dendra amyE5' & This work \\
pJPR1-PAGFP & bla amyE3' cat Pxyl pagfp amyE5' & This work \\
pJPR1-DivIVA-PAGFP & bla amyE3' cat Pxyl divIVA_pagfp amyE5' & This work \\
pJPR1-DivIVA-Dendra & bla amyE3' cat Pxyl divIVA_dendra amyE5' & This work \\
\hline
\end{tabular}

Table 3 | B. subtilis and E. coli strains used in this study.

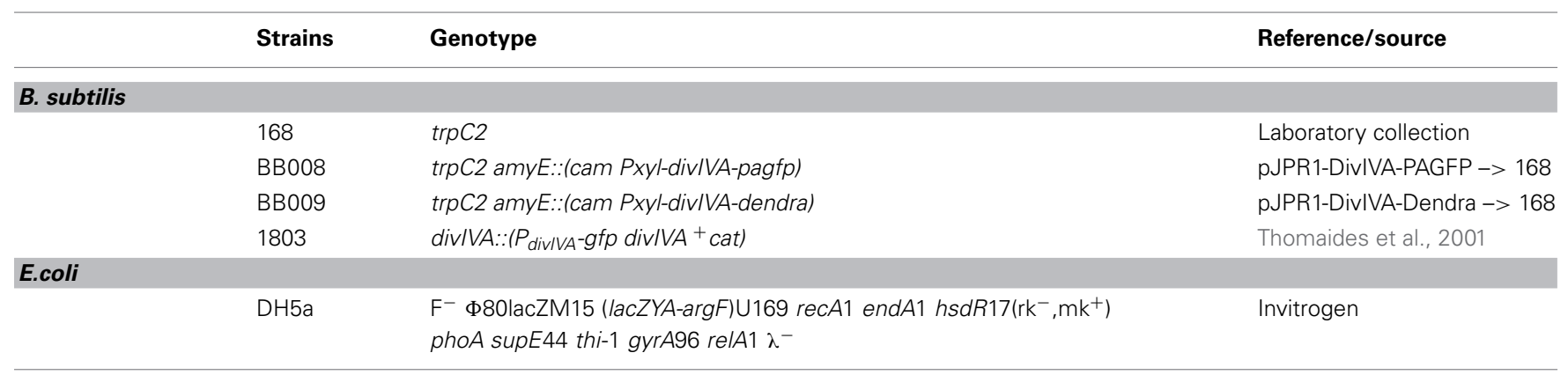

Eswaramoorthy et al., 2011). Non-dividing cells show DivIVA accumulations at both cell poles, while actively dividing cells were reported to have DivIVA at the poles and at the site of ongoing septation. A recent study using 3D structured illumination revealed that DivIVA localizes in a ring-like fashion at the septum, while patches of DivIVA remain at the cell poles (Eswaramoorthy et al., 2011). The polar patches described by Eswaramoorthy and colleagues have apparently less DivIVA compared to the DivIVA concentration at the septum, and hence, the question remains whether DivIVA molecules may move from the cell pole to midcell. We reinvestigated DivIVA localization in growing cells of strain 1803 (Thomaides et al., 2001) using time lapse microscopy (Figure 1). DivIVA-GFP localization in exponentially growing cells seems to concentrate almost entirely at the septum. When the fluorescence intensity of DivIVA at midcell is quantified starting with fully matured septa over time a steady decrease indicates the loss of DivIVA molecules from the septum with ongoing division or pole formation (Figure 1). At the same time, new septa occurring on either side of the old septum gain DivIVA molecules as indicated by the strong increase in fluorescence. A simple and plausible explanation of this dynamic protein behavior would be the migration of polar DivIVA material to the new sites of division. It should be noted that the total fluorescence at the new septa exceeds the initial fluorescence at the cell poles (Figure 1). Using time lapse microscopy it is not possible to discriminate between proteolysis/new synthesis of DivIVA and dynamic relocalization of DivIVA.

\section{DivIVA LOCALIZATION IS DYNAMIC IN B. subtilis}

Protein mobility in vivo can be quantified with fluorescence recovery after photo-bleaching (FRAP). We bleached part of the DivIVA-GFP signal at one cell pole or at the septum and measured reoccurrence of GFP signals. Within few minutes the majority of the signal recovered in the bleached area (Figures 2A-D). This recovery is in contrast to results published earlier (Eswaramoorthy et al., 2011) where FRAP experiments were reported to have only little recovery. However, images in that publication reveal already slight recovery after $1 \mathrm{~min}$ (Eswaramoorthy et al., 2011). In order to rule out the possibility that recovery of fluorescence might exclusively be due to 


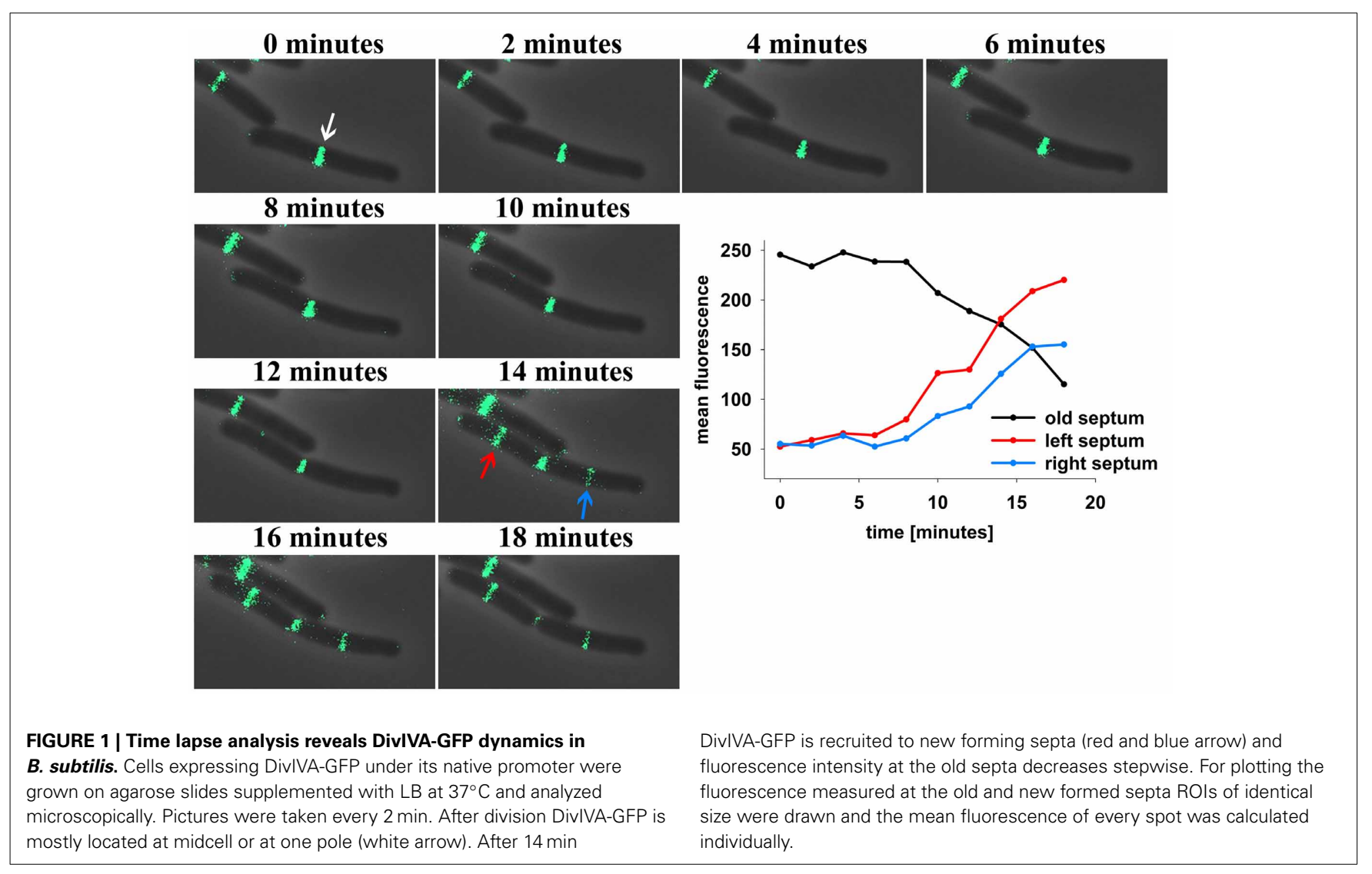

new synthesis of DivIVA-GFP, we blocked protein biosynthesis (see material and methods) before performing FRAP experiments. Strikingly, recovery of DivIVA-GFP in cells with inhibited protein biosynthesis was almost identical to the FRAP experiments without inhibitor (Figure S1). These results support that DivIVA dynamically reassembles at new division sites with material recruited from cell poles.

In order to unambiguously determine whether DivIVA molecules at new division site recruits material from old divisions (cell poles) we constructed a $B$. subtilis strain encoding for a DivIVA-PA-GFP construct. The photoactivatable GFP is nonfluorescent when the proteins are synthesized. Upon activation with a laser flash, PA-GFP is activated and the classical GFP fluorescence is readily observed (Patterson and Lippincott-Schwartz, 2002). Photoactivation of DivIVA-PA-GFP was achieved with a $0.5 \mathrm{~s}$ laser pulse of $405 \mathrm{~nm}$ (see material and methods). We converted PA-GFP at the pole region of growing cells and immediately after photoactivation green fluorescence was observed (Figure 3). Over time the green fluorescence was redistributed in the cell and accumulated at midcell position, while a clear decrease in fluorescence at the cell poles was observed. This behavior mimicked the DivIVA-GFP dynamics seen in the FRAP experiments. Control experiments indicated that imaging PAGFP after photoactivation using the InsightSSI light source did not yield any conversion (data not shown), ruling out that new fluorescent material was generated during the time lapse imaging process. These data clearly suggest that DivIVA molecules are dynamic and material from old division sites (cell poles) contribute to the DivIVA assemblies at active division sites. Efficient activation of PA-GFP in bacteria needed a significant input of energy. Although we confirmed cell viability by cell growth, we realized that cells with efficient PA-GFP activation often died or grew slower, likely due to phototoxic effects.

Milder conditions are apparently needed to avoid phototoxic effects. Therefore, we turned our attention to a photoconvertible fluorophore, Dendra2 (Gurskaya et al., 2006; Chudakov et al., 2007). Dendra2 is a monomeric protein with a green-to-red photoconversion upon blue light exposure (Gurskaya et al., 2006). Dendra2 was reported to fold efficiently in bacteria and its photostability makes it ideal for long-term protein tracking (Gurskaya et al., 2006). We have constructed a DivIVA-Dendra2 and analyzed localization of the translational fusion protein in growing cells (Figure 4). Green fluorescence was readily observed at cell poles and septa, undistinguishable from the DivIVA-GFP fusion. DivIVA-Dendra was converted by a very fast $(0.05 \mathrm{~s}) 405 \mathrm{~nm}$ laser flash. Immediately after the conversion time lapse analysis revealed the generation of a red fluorophore at the site of conversion. Since imaging of green fluorescence at $488 \mathrm{~nm}$ exposure slowly, but significantly convert more DivIVA-Dendra2 from green to red, we only followed the red signal. Clearly, the red, converted DivIVA redistributed and accumulated over time at a new septum that was formed (Figure 4 and Figure S2). Control experiments using the same imaging conditions without laser event revealed no photoconversion (data not shown). 

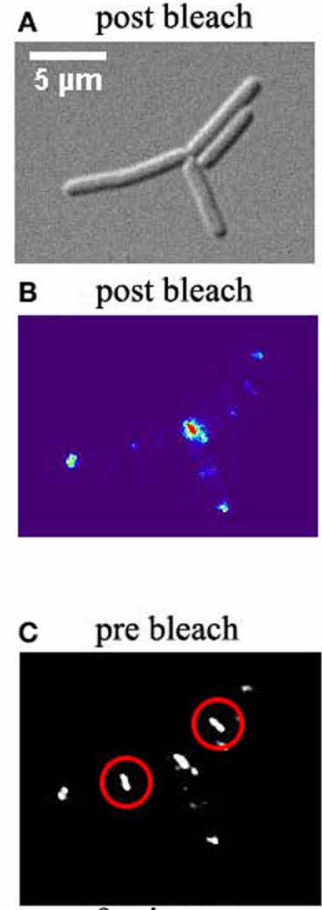

9 minutes

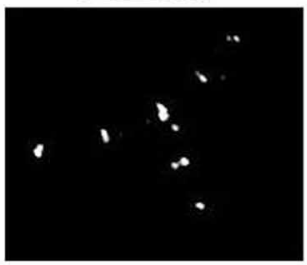

18 minutes

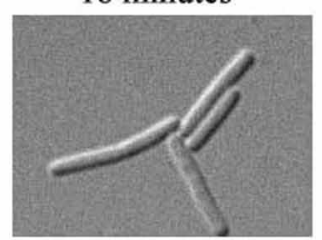

18 minutes

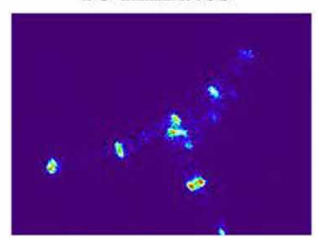

0 minutes

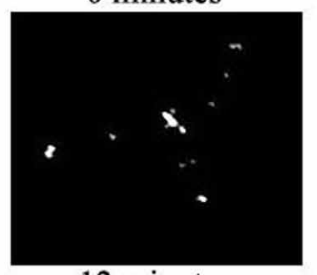

12 minutes

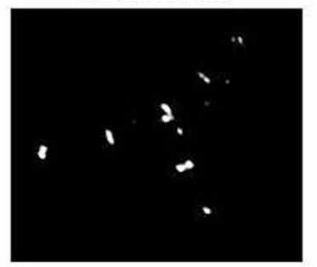

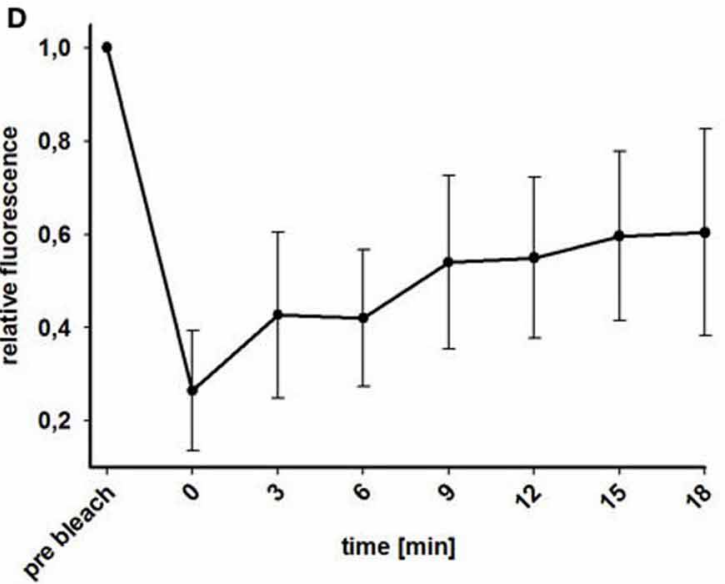

3 minutes

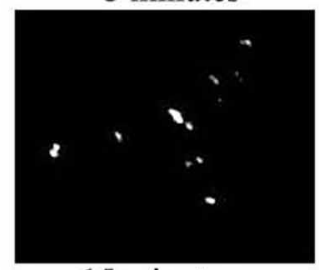

15 minutes

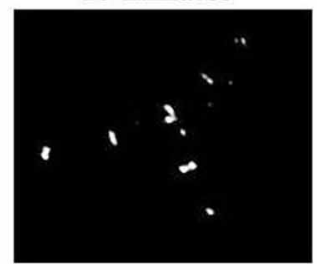

6 minutes

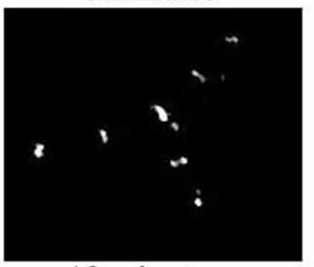

18 minutes

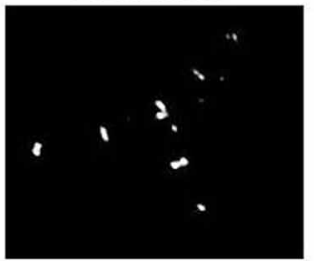

FIGURE 2 | Fluorescence recovery after photobleaching of DivIVA-GFP. Cells expressing DivIVA-GFP under control of the native promoter were grown on agarose slides supplemented with LB. (A) DIC images of B. subtilis cells expressing DivIVA-GFP directly after a bleaching event and after $18 \mathrm{~min}$ are shown (B) Heat maps of the GFP signal and time lapse images indicate fluorescence distribution (C). DivIVA-GFP was bleached (red circles) as described in material and methods. Pictures were taken every 3 min after the bleaching event. Images show GFP fluorescence. (D) Quantification of the recovery rate of bleached spots; $n=6$.
Thus, DivIVA-Dendra2 which was converted at an ongoing site of division or a cell pole redistributes to new division sites.

\section{DISCUSSION}

Regulation of division site selection is a primary problem in cell biology. Although intensively studied the exact mechanisms of septum placement is not even fully understood in simple rodshaped bacteria. Particularly puzzling was the finding that the Gram negative bacterium E. coli used an oscillating Min system to position its cytokinetic machinery while a geometrically similar rod, B. subtilis seemed to have a static Min system tethered to cell poles by DivIVA. Recent observations have shed some doubt on the static nature of the B. subtilis Min localization (Bramkamp et al., 2008; Gregory et al., 2008; Van Baarle and Bramkamp, 2010). However, it remained unclear whether only the MinCD complex might be dynamic and whether the topological factors MinJ and DivIVA are static components. An attempt to use super-resolution microscopy showed that DivIVA accumulates at the sites of ongoing divisions and reduces to a patch-like focus at the old cell pole (Eswaramoorthy et al., 2011). However, FRAP experiments in this study led to the suggestion that DivIVA molecules are not dynamically re-localized to new sites of division. We revisited this question based on time lapse analysis with quantitative analysis of DivIVA-GFP in growing B. subtilis. Quantification of GFP signals revealed that the loss of GFP at the old division site and accumulation of GFP at the new sites of division runs in parallel (Figure 1). In accord with this, FRAP experiments in presence and absence of antibiotics inhibiting protein biosynthesis revealed a slow recovery of DivIVA. A fundamental difference to the fast oscillation of the topological factor in the E. coli Min system, MinE, which oscillates within seconds, DivIVA dynamics are within minutes (Figures 1, 2). This slow redistribution of DivIVA could also be explained by a localized proteolysis at the old pole and assembly of newly synthesized 


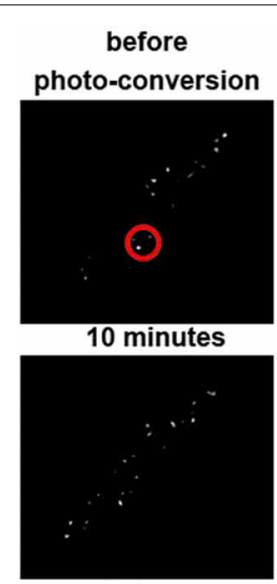

before

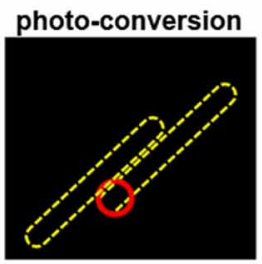

10 minutes

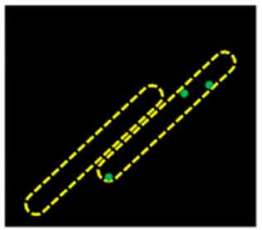

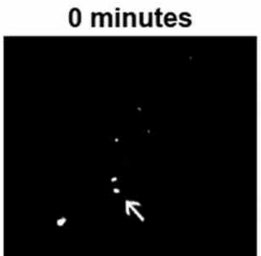

15 minutes

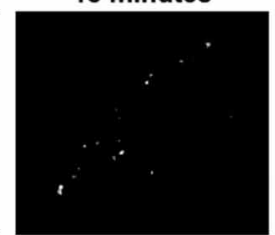

0 minutes

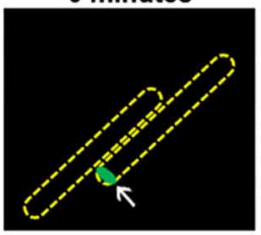

15 minutes

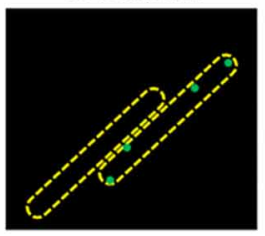

\section{5 minutes}

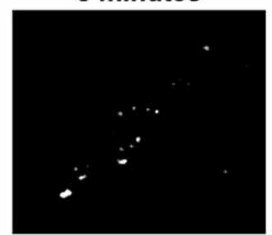

20 minutes

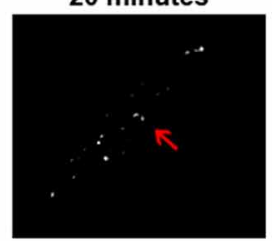

5 minutes

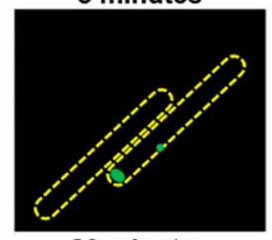

20 minutes

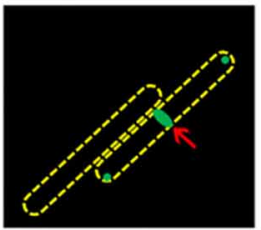

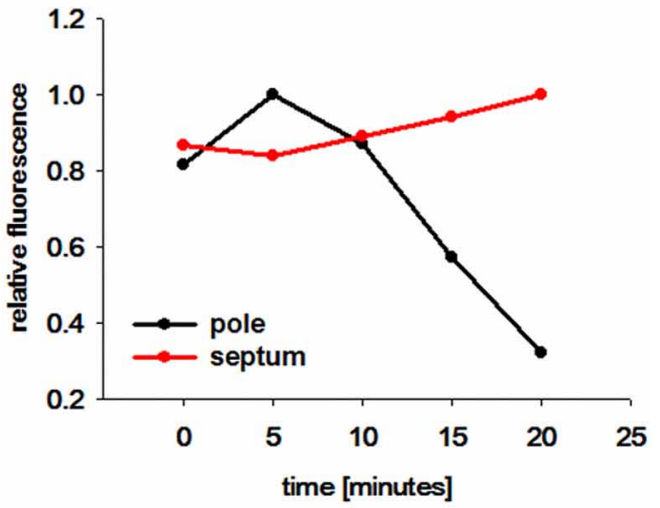

FIGURE 3 | DivIVA-PA-GFP is dynamically recruited from the cell pole to the septa. DivIVA-PA-GFP fluorescence was imaged before photo-activation using DIC and FITC specific filters. Photoactivation was performed using a laser at $405 \mathrm{~nm}$ (red circle). After photoactivation DivIVA-PA-GFP (white arrow) is localized at the cell pole. Although, the signal gets more diffuse over time, accumulation at a new septum after
20 min becomes evident (red arrow). A cartoon of DivIVA-PA-GFP dynamics is drawn below. The relative fluorescence of the pole (white arrow) and the new formed septa (red arrow) was measured. The relative fluorescence of the according spots were calculated (CTF was calculated and the highest CTF of all spots were set as 1) and plotted. For every time point spots were chosen individually. material at the new sites of septation. The data presented here cannot exclude localized proteolysis of DivIVA at the cell poles. In order to demonstrate clearly a dynamic component of the spatiotemporal DivIVA distribution with the cell we used photoactivatable and photoconvertible fluorophores in this study. PA-GFP and Dendra 2 are stably activated or converted by a laser pulse and the protein portion that was activated/converted can be tracked precisely over time. With this technique we could clearly show that DivIVA molecules from previous division sites contribute to the formation of new septa (Figures 3, 4). Hence, our data indicate that DivIVA in B. subtilis is not static but dynamic, leaving old division sites (cell poles) and accumulating at nascent septa (Figure 5). Cells in stationary phase or otherwise non-growing cells, have DivIVA at both cell poles, however, actively growing cells, reduce the DivIVA concentration at the old septa/poles fast and redeploy DivIVA molecules to build DivIVA rings at active division sites (Figure 5). Our data contribute to the new ideas of Min functioning in cell division in B. subtilis. In contrast to a long standing hypothesis the Min system in B. subtilis is not statically protecting the old poles from aberrant division, but rather prevents reinitiation of septation close to active septa (Bramkamp et al., 2008; Gregory et al., 2008; Van Baarle and Bramkamp, 2010; Eswaramoorthy et al., 2011). The avoidance of reinitiation seems to be regulated at different levels. The MinCD system likely prevents reassembly of mature FtsZ rings, while proteolysis of free FtsL may prevent reassembly of membrane components of the divisome (Wadenpohl and Bramkamp, 2010).

Interestingly, a dynamic DivIVA/Min system in B. subtilis provokes a couple of questions about the molecular mechanism, by which this dynamic behavior is regulated. DivIVA was shown to bind to curved membrane areas (Lenarcic et al., 2009; Ramamurthi and Losick, 2009). A molecular bridging model for the formation of DivIVA assemblies at curved membranes has been presented (Lenarcic et al., 2009). The molecular bridging model suggested that DivIVA complexes with fewer contacts might diffuse away from the membrane. In dividing $B$. subtilis cells this could simply be triggered by pole formation where the cell pole rounds up, after daughter cell separation. However, other cellular factors might play a role in DivIVA dynamics as well. Several groups have reported phosphorylation of DivIVA 


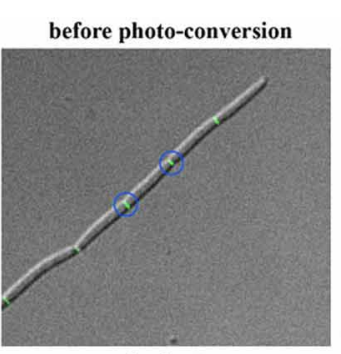

5 minutes

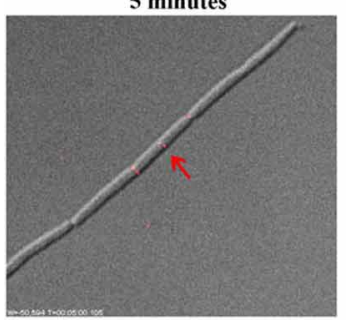

10 minutes
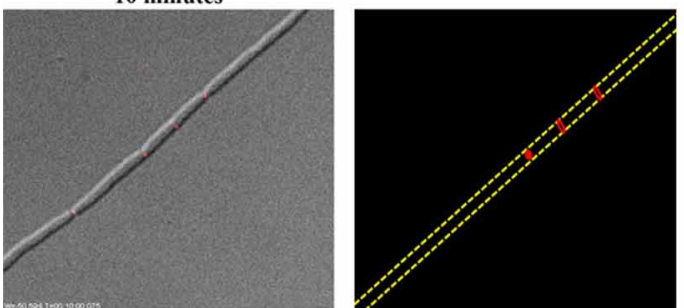

FIGURE 4 | DivIVA-Dendra2 is dynamically recruited from the cell pole to the septa. DivIVA-Dendra2 fluorescence (green and red) was imaged before photoconversion using DIC, FITC, or TRITC specific filters. After photoconversion using a $405 \mathrm{~nm}$ laser (cyan circles) only red fluorescence (TRITC) and DIC was monitored to prevent additional photoconversion. After $5 \mathrm{~min}$ DivIVA-Dendra2 is recruited from the place of photoconversion (black and blue circle) to new septa forming (red

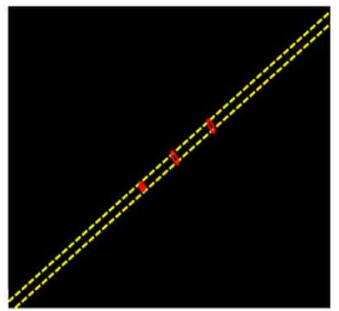

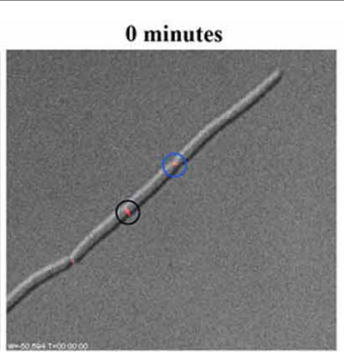
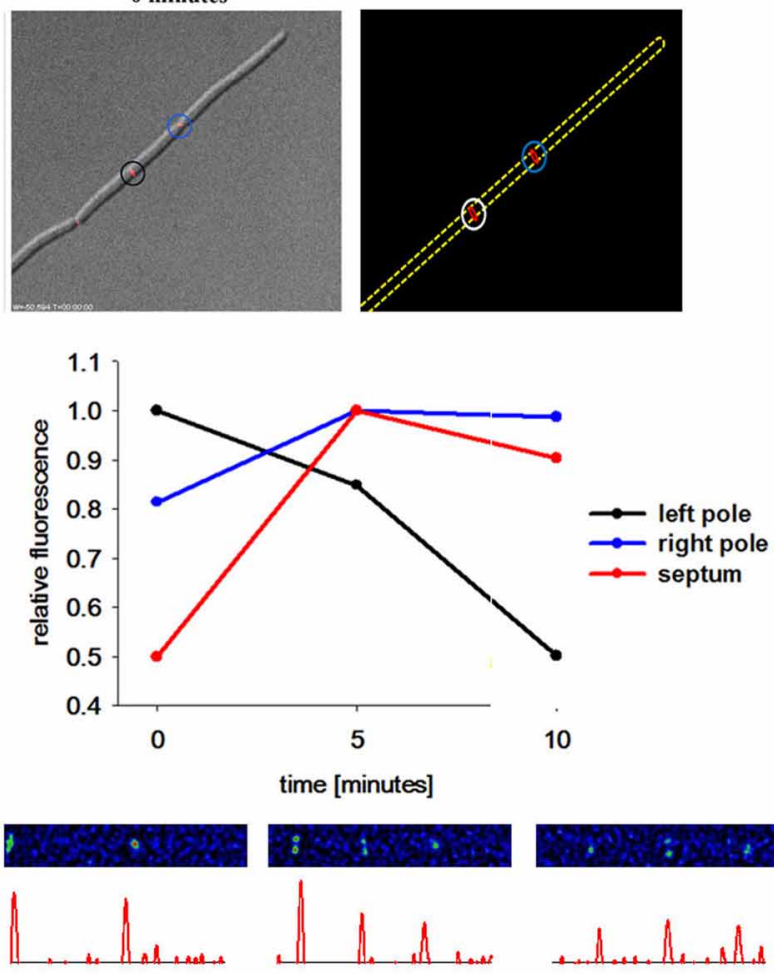

arrow). A cartoon of the photoconversion is shown. The relative fluorescence of the left pole (black circle), the right pole (blue circle), and the new formed septa (red arrow) was measured. The relative fluorescence of the corresponding spots were calculated (CTF was calculated and the highest CTF of each spot was set as 1) and plotted. For every time point spots were chosen individually. Heat maps and corresponding histograms are shown below.
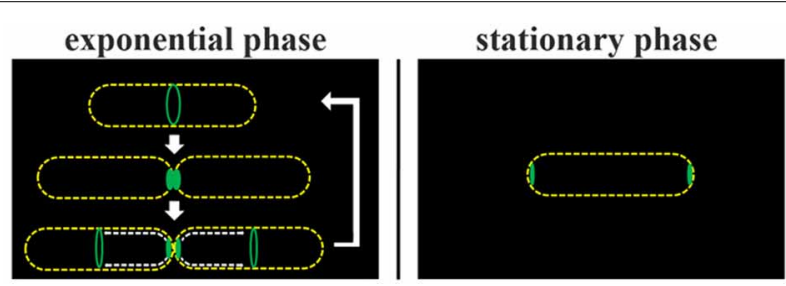

FIGURE 5 | Model of DivIVA dynamics in B. subtilis. During cytokinesis DivIVA rings at constricting septa collapse into foci/patches (Eswaramoorthy et al., 2011). Exponentially growing B. subtilis cells redeploy at least a fraction of DivIVA molecules from old division sites (cell poles) to nascent septa (broken white lines). Only in non-dividing cells DivIVA is clearly seen as accumulation at both cell poles.

homologs in actinobacteria and firmicutes (Kang et al., 2005, 2008; Beilharz et al., 2012; Hempel et al., 2012; Saalbach et al., 2013). Maybe reversible phosphorylation of DivIVA could be a cue to shuttle the protein between a membrane attached and soluble from. The function and dynamics of the B. subtilis Min system apparently needs revisiting and will likely bring up some surprises.

\section{ACKNOWLEDGMENTS}

The authors thank Dr. Astrid Schauss (CECAD, Cologne) for the kind gift of PA-GFP and Dendra2 source plasmids. Financial support from the Deutsche Forschungsgemeinschaft, DFG (BR2915/2-1) is gratefully acknowledged.

\section{SUPPLEMENTARY MATERIAL}

The Supplementary Material for this article can be found online at: http://www.frontiersin.org/journal/10.3389/fmicb.2014. 00059/abstract

\section{REFERENCES}

Adams, D. W., and Errington, J. (2009). Bacterial cell division: assembly, maintenance and disassembly of the Z ring. Nat. Rev. Microbiol. 7, 642-653. doi: $10.1038 /$ nrmicro2 198

Adler, H. I., Fisher, W. D., Cohen, A., and Hardigree, A. A. (1967). MINIATURE Escherichia coli cells deficient in DNA. Proc. Natl. Acad. Sci. U.S.A. 57, 321-326. doi: 10.1073/pnas.57.2.321

Akerlund, T., Bernander, R., and Nordstrom, K. (1992). Cell division in Escherichia coli $\operatorname{minB}$ mutants. Mol. Microbiol. 6, 2073-2083. doi: 10.1111/j.1365-2958. 1992.tb01380.x

Beilharz, K., Novakova, L., Fadda, D., Branny, P., Massidda, O., and Veening, J. W. (2012). Control of cell division in Streptococcus pneumoniae by the conserved Ser/Thr protein kinase StkP. Proc. Natl. Acad. Sci. U.S.A. 109, E905-E913. doi: 10.1073/pnas.1119172109 
Bi, E., and Lutkenhaus, J. (1990). Interaction between the min locus and ftsZ. J. Bacteriol. 172, 5610-5616.

Bi, E. F., and Lutkenhaus, J. (1991). FtsZ ring structure associated with division in Escherichia coli. Nature 354, 161-164. doi: 10.1038/354161a0

Bramkamp, M., Emmins, R., Weston, L., Donovan, C., Daniel, R. A., and Errington, J. (2008). A novel component of the division-site selection system of Bacillus subtilis and a new mode of action for the division inhibitor MinCD. Mol. Microbiol. 70, 1556-1569. doi: 10.1111/j.1365-2958.2008.06501.x

Bramkamp, M., and Van Baarle, S. (2009). Division site selection in rodshaped bacteria. Curr. Opin. Microbiol. 12, 683-688. doi: 10.1016/j.mib.2009. 10.002

Cha, J. H., and Stewart, G. C. (1997). The divIVA minicell locus of Bacillus subtilis. J. Bacteriol. 179, 1671-1683.

Chudakov, D. M., Lukyanov, S., and Lukyanov, K. A. (2007). Using photoactivatable fluorescent protein Dendra2 to track protein movement. Biotechniques 42, 553-563. doi: 10.2144/000112470

De Boer, P. A., Crossley, R. E., Hand, A. R., and Rothfield, L. I. (1991), The MinD protein is a membrane ATPase required for the correct placement of the Escherichia coli division site. EMBO J. 10 4371-4380.

De Boer, P. A., Crossley, R. E., and Rothfield, L. I. (1988). Isolation and properties of $\min B$, a complex genetic locus involved in correct placement of the division site in Escherichia coli. J. Bacteriol. 170, 2106-2112.

Edwards, D. H., and Errington, J. (1997). The Bacillus subtilis DivIVA protein targets to the division septum and controls the site specificity of cell division. Mol. Microbiol. 24, 905-915. doi: 10.1046/j.1365-2958.1997.3811764.x

Edwards, D. H., Thomaides, H. B., and Errington, J. (2000). Promiscuous targeting of Bacillus subtilis cell division protein DivIVA to division sites in Escherichia coli and fission yeast. EMBO J. 19, 2719-2727. doi: 10.1093/emboj/19.11. 2719

Errington, J., Daniel, R. A., and Scheffers, D. J. (2003). Cytokinesis in bacteria. Microbiol. Mol. Biol. Rev. 67, 52-65. doi: 10.1128/MMBR.67.1.52-65. 2003

Eswaramoorthy, P., Erb, M. L., Gregory, J. A., Silverman, J., Pogliano, K., Pogliano, J., et al. (2011). Cellular architecture mediates DivIVA ultrastructure and regulates min activity in Bacillus subtilis. MBio 2:e0257. doi: 10.1128/mBio. 00257-11

Gavet, O., and Pines, J. (2010). Progressive activation of CyclinB1-Cdk1 coordinates entry to mitosis. Dev. Cell 18, 533-543. doi: 10.1016/j.devcel.2010.02.013

Gregory, J. A., Becker, E. C., and Pogliano, K. (2008). Bacillus subtilis MinC destabilizes FtsZ-rings at new cell poles and contributes to the timing of cell division. Genes Dev. 22, 3475-3488. doi: 10.1101/gad.1732408

Gurskaya, N. G., Verkhusha, V. V., Shcheglov, A. S., Staroverov, D. B., Chepurnykh, T. V., Fradkov, A. F., et al. (2006). Engineering of a monomeric green-to-red photoactivatable fluorescent protein induced by blue light. Nat. Biotechnol. 24 461-465. doi: 10.1038/nbt1191

Hamoen, L. W., and Errington, J. (2003). Polar targeting of DivIVA in Bacillus subtilis is not directly dependent on FtsZ or PBP 2B. J. Bacteriol. 185, 693-697. doi: 10.1128/JB.185.2.693-697.2003

Hempel, A. M., Cantlay, S., Molle, V., Wang, S. B., Naldrett, M. J., Parker, J. L., et al. (2012). The Ser/Thr protein kinase AfsK regulates polar growth and hyphal branching in the filamentous bacteria Streptomyces. Proc. Natl. Acad. Sci. U.S.A. 109, E2371-E2379. doi: 10.1073/pnas.1207409109

Hu, Z., and Lutkenhaus, J. (1999). Topological regulation of cell division in Escherichia coli involves rapid pole to pole oscillation of the division inhibitor MinC under the control of MinD and MinE. Mol. Microbiol. 34, 82-90. doi: 10.1046/j.1365-2958.1999.01575.x

Hu, Z., and Lutkenhaus, J. (2001). Topological regulation of cell division in $E$. coli. spatiotemporal oscillation of MinD requires stimulation of its ATPase by MinE and phospholipid. Mol. Cell 7, 1337-1343. doi: 10.1016/S1097-2765(01) 00273-8

Kang, C. M., Abbott, D. W., Park, S. T., Dascher, C. C., Cantley, L. C., and Husson, R. N. (2005). The Mycobacterium tuberculosis serine/threonine kinases PknA and PknB: substrate identification and regulation of cell shape. Genes Dev. 19, 1692-1704. doi: 10.1101/gad.1311105

Kang, C. M., Nyayapathy, S., Lee, J. Y., Suh, J. W., and Husson, R. N. (2008). Wag31, a homologue of the cell division protein DivIVA, regulates growth, morphology and polar cell wall synthesis in mycobacteria. Microbiology 154, 725-735. doi: 10.1099/mic.0.2007/014076-0
Lee, S., and Price, C. W. (1993). The minCD locus of Bacillus subtilis lacks the minE determinant that provides topological specificity to cell division. Mol. Microbiol. 7, 601-610. doi: 10.1111/j.1365-2958.1993. tb01151.x

Lenarcic, R., Halbedel, S., Visser, L., Shaw, M., Wu, L. J., Errington, J., et al. (2009). Localisation of DivIVA by targeting to negatively curved membranes. EMBO J. 28, 2272-2282. doi: 10.1038/emboj.2009.129

Loose, M., Fischer-Friedrich, E., Ries, J., Kruse, K., and Schwille, P. (2008). Spatial regulators for bacterial cell division self-organize into surface waves in vitro. Science 320, 789-792. doi: 10.1126/science. 1154413

Lutkenhaus, J. (2007). Assembly dynamics of the bacterial MinCDE system and spatial regulation of the $\mathrm{Z}$ ring. Annu. Rev. Biochem. 76, 539-562. doi: 10.1146/ annurev.biochem.75.103004.142652

Lutkenhaus, J. (2012). The ParA/MinD family puts things in their place. Trends Microbiol. 20, 411-418. doi: 10.1016/j.tim.2012.05.002

Marston, A. L., and Errington, J. (1999). Selection of the midcell division site in Bacillus subtilis through MinD-dependent polar localization and activation of MinC. Mol. Microbiol. 33, 84-96. doi: 10.1046/j.1365-2958.1999. 01450.x

Marston, A. L., Thomaides, H. B., Edwards, D. H., Sharpe, M. E., and Errington, J. (1998). Polar localization of the MinD protein of Bacillus subtilis and its role in selection of the mid-cell division site. Genes Dev. 12, 3419-3430. doi: 10.1101/ gad.12.21.3419

Oliva, M. A., Halbedel, S., Freund, S. M., Dutow, P., Leonard, T. A., Veprintsev, D. B., et al. (2010). Features critical for membrane binding revealed by DivIVA crystal structure. EMBO J. 29, 1988-2001. doi: 10.1038/emboj. 2010.99

Patrick, J. E., and Kearns, D. B. (2008). MinJ (YvjD) is a topological determinant of cell division in Bacillus subtilis. Mol. Microbiol. 70, 1166-1179. doi: 10.1111/j. 1365-2958.2008.06469.x

Patterson, G. H., and Lippincott-Schwartz, J. (2002). A photoactivatable GFP for selective photolabeling of proteins and cells. Science 297, 1873-1877. doi: $10.1126 /$ science. 1074952

Perry, S. E., and Edwards, D. H. (2004). Identification of a polar targeting determinant for Bacillus subtilis DivIVA. Mol. Microbiol. 54, 1237-1249. doi: 10.1111/j. 1365-2958.2004.04363.x

Ramamurthi, K. S., and Losick, R. (2009). Negative membrane curvature as a cue for subcellular localization of a bacterial protein. Proc. Natl. Acad. Sci. U.S.A. 106, 13541-13545. doi: 10.1073/pnas.0906851106

Raskin, D. M., and De Boer, P. A. (1999a). MinDE-dependent pole-to-pole oscillation of division inhibitor MinC in Escherichia coli. J. Bacteriol. 181, 6419-6424.

Raskin, D. M., and De Boer, P. A. (1999b). Rapid pole-to-pole oscillation of a protein required for directing division to the middle of Escherichia coli. Proc. Natl. Acad. Sci. U.S.A. 96, 4971-4976. doi: 10.1073/pnas.96.9. 4971

Reeve, J. N., Mendelson, N. H., Coyne, S. I., Hallock, L. L., and Cole, R. M. (1973). Minicells of Bacillus subtilis. J. Bacteriol. 114, 860-873.

Rothfield, L., Taghbalout, A., and Shih, Y. L. (2005). Spatial control of bacterial division-site placement. Nat. Rev. Microbiol. 3, 959-968. doi: 10.1038/ nrmicrol290

Saalbach, G., Hempel, A. M., Vigouroux, M., Flärdh, K., Buttner, M. J., and Naldrett, M. J. (2013). Determination of phosphorylation sites in the DivIVA cytoskeletal protein of Streptomyces coelicolor by targeted LC-MS/MS. J. Proteome Res. 12, 4187-4192. doi: 10.1021/pr400524d

Thomaides, H. B., Freeman, M., El Karoui, M., and Errington, J. (2001). Division site selection protein DivIVA of Bacillus subtilis has a second distinct function in chromosome segregation during sporulation. Genes Dev. 15, 1662-1673. doi: 10.1101/gad.197501

Van Baarle, S., and Bramkamp, M. (2010). The MinCDJ system in Bacillus subtilis prevents minicell formation by promoting divisome disassembly. PLoS ONE 5:e9850. doi: 10.1371/journal.pone.0009850

Varley, A. W., and Stewart, G. C. (1992). The divIVB region of the Bacillus subtilis chromosome encodes homologs of Escherichia coli septum placement $(\min C D)$ and cell shape $(m r e B C D)$ determinants. J. Bacteriol. 174, 6729-6742.

Wadenpohl, I., and Bramkamp, M. (2010). DivIC stabilizes FtsL against RasP cleavage. J. Bacteriol. 192, 5260-5263. doi: 10.1128/JB.00287-10 
Zhao, C. R., De Boer, P. A., and Rothfield, L. I. (1995). Proper placement of the Escherichia coli division site requires two functions that are associated with different domains of the MinE protein. Proc. Natl. Acad. Sci. U.S.A. 92, 4313-4317. doi: 10.1073/pnas.92.10.4313

Conflict of Interest Statement: The authors declare that the research was conducted in the absence of any commercial or financial relationships that could be construed as a potential conflict of interest.

Received: 15 November 2013; paper pending published: 10 December 2013; accepted: 29 January 2014; published online: 18 February 2014.
Citation: Bach JN, Albrecht $N$ and Bramkamp $M$ (2014) Imaging DivIVA dynamics using photo-convertible and activatable fluorophores in Bacillus subtilis. Front. Microbiol. 5:59. doi: 10.3389/fmicb.2014.00059

This article was submitted to Microbial Physiology and Metabolism, a section of the journal Frontiers in Microbiology.

Copyright (C) 2014 Bach, Albrecht and Bramkamp. This is an open-access article distributed under the terms of the Creative Commons Attribution License (CC BY). The use, distribution or reproduction in other forums is permitted, provided the original author(s) or licensor are credited and that the original publication in this journal is cited, in accordance with accepted academic practice. No use, distribution or reproduction is permitted which does not comply with these terms. 